Corrigendum

\title{
The Winding Road to Industrial Safety: Evidence on the Effects of Environmental Liability on Accident Prevention in Germany
}

\author{
R. Schwarze and O. Hoffmeister
}

The Geneva Papers (2010) 35, 668. doi:10.1057/gpp.2010.31

Correction to: The Geneva Papers (2010) 35(3): 416-434. doi: 10.1057/gpp.2010.16

The authors wish to make the following amendments to their affiliations:

Reimund Schwarze, Economics, Helmholtz Centre for Environmental ResearchUFZ, Permoser Street 15, Leipzig D-04318, Germany, reimund.schwarze@ufz.de

Onno Hoffmeister, University of Hamburg, Von-Melle-Park 5, D-20146 Hamburg, Germany, onno.hoffmeister@ec.europa.eu 